\title{
Fabrication of flexible thermoelectric microcoolers using planar thin-film technologies
}

\author{
L M Goncalves ${ }^{1}$, J G Rocha ${ }^{1}$, C Couto ${ }^{1}$, P Alpuim ${ }^{2}$, Gao Min ${ }^{3}$, \\ D M Rowe ${ }^{3}$ and $\mathbf{J}$ H Correia ${ }^{1}$ \\ ${ }^{1}$ Department of Industrial Electronics, University of Minho, Campus de Azurém, \\ 4800-058 Guimaraes, Portugal \\ ${ }^{2}$ Department of Physics, University of Minho, Campus de Azurém, 4800-058 Guimaraes, \\ Portugal \\ ${ }^{3}$ University of Cardiff, School of Engineering, Cardiff, UK \\ E-mail: lgoncalves@dei.uminho.pt
}

Received 15 December 2006, in final form 23 February 2007

Published 2 July 2007

Online at stacks.iop.org/JMM/17/S168

\begin{abstract}
The present work reports on the fabrication and characterization of a planar Peltier cooler on a flexible substrate. The device was fabricated on a $12 \mu \mathrm{m}$ thick Kapton(c) polyimide substrate using $\mathrm{Bi}_{2} \mathrm{Te}_{3}$ and $\mathrm{Sb}_{2} \mathrm{Te}_{3}$ thermoelectric elements deposited by thermal co-evaporation. The cold area of the device is cooled with four thermoelectric junctions, connected in series using metal contacts. Plastic substrates add uncommon mechanical properties to the composite film-substrate and enable integration with novel types of flexible electronic devices. Films were deposited by co-evaporation of tellurium and bismuth or antimony to obtain $\mathrm{Bi}_{2} \mathrm{Te}_{3}$ or $\mathrm{Sb}_{2} \mathrm{Te}_{3}$, respectively. Patterning of the thermoelectric materials using lift-off and wet-etching techniques was studied and compared. The performance of the Peltier microcooler was analysed by infrared image microscopy, on still-air and under vacuum conditions, and a maximum temperature difference of $5^{\circ} \mathrm{C}$ was measured between the cold and the hot sides of the device.
\end{abstract}

(Some figures in this article are in colour only in the electronic version)

\section{Introduction}

Microcoolers with efficient cooling capacity, small area (down to parts of a millimetre) and short response time are in high demand, due to their unique properties. Thermoelectric cooling is widely employed in electronics to stabilize the temperature of devices, decrease noise levels and increase operation speed.

Since Peltier devices are reversible, they can also be used as electrical generators, converting thermal into electrical energy. Thermoelectric microgenerators can be used in various small low-power devices such as hearing aids, wrist watches or wearable electronics. This has been shown recently by Seiko and Citizen with their commercialized thermoelectrically driven low-power wristwatches. Nevertheless, only a few approaches to manufacturing high-performance thermoelectric devices with small dimensions are found in the literature [1-6].

Large-area Peltier devices (with columnar structure) to work around room temperature (RT) have been commercialized for a long time, with thermoelectric elements made of tellurium compounds (n-type $\mathrm{Bi}_{2} \mathrm{Te}_{3}$ and p-type $\mathrm{Sb}_{2} \mathrm{Te}_{3}$ ). In theory, this configuration could be scaled down to microdevice fabrication, but the fabrication processes used for such devices are not scalable to the micrometer range. Polycrystalline SiGe alloys and polycrystalline Si have been used in the fabrication of microcoolers due to silicon fabrication compatibility [7] but the performance is very low compared with that of tellurium compounds.

Using a lateral (in-plane) configuration, thin-film techniques can be used to scale down the thermoelectric coolers and generators to microdevice dimensions, using 


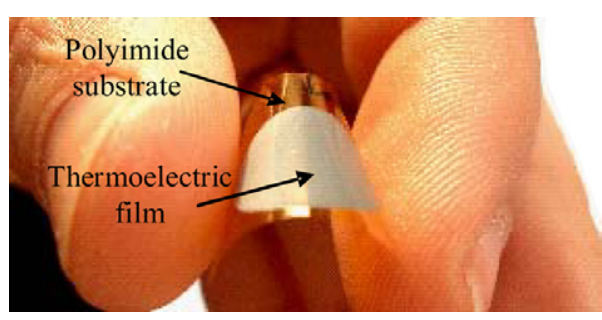

Figure 1. $\mathrm{A} \mathrm{Bi}_{2} \mathrm{Te}_{3}$ thin film deposited on top of a flexible polyimide substrate.

tellurium compounds with performance similar to that of bulk materials [8]. In the present work, planar thin-film technology will be used to fabricate such devices. A microcooler was fabricated on a flexible polyimide Kapton(c) substrate, adding uncommon mechanical properties (figure 1) to the composite film-substrate and enabling integration with novel types of devices. The polyimide substrate is excellent for thermoelectric microcoolers in the lateral configuration, because of its small thermal conductivity of $0.15 \mathrm{~W} \mathrm{~m}^{-1} \mathrm{~K}^{-1}$ and its thermal expansion coefficient (about $20 \times 10^{-6} \mathrm{~K}^{-1}$ ) of the same order of magnitude as that of the thermoelectric films, thus reducing thermal stresses induced during cooling down from the temperature of deposition (200-300 ${ }^{\circ} \mathrm{C}$ ). Figure 1 shows a thermoelectric film deposited on top of a polyimide substrate.

\section{Device simulation}

Each $\mathrm{p}-\mathrm{n}$ thermoelectric pair of the Peltier cooler can be modelled [9] by equation (1):

$$
\Delta T=\frac{1}{K_{\mathrm{eq}}}\left[\left(\alpha_{\mathrm{p}}-\alpha_{\mathrm{n}}\right) T_{\mathrm{c}} I-\frac{1}{2} R_{\mathrm{eq}} I^{2}-Q_{\mathrm{LOAD}}\right]
$$

where $\Delta T$ is the maximum temperature difference achieved by the microcooler, $\alpha_{\mathrm{n}}$ and $\alpha_{\mathrm{p}}$ are the Seebeck coefficients of the n- and p-type materials, $T_{\mathrm{c}}$ is the cold side temperature, $I$ is the current injected into the device and $Q_{\mathrm{LOAD}}$ is the sum of all thermal loads applied on the cold side of the device (including convection and radiation). $R_{\text {eq }}$ and $K_{\text {eq }}$ are the equivalent electrical resistance and thermal conductance of n- and p-type elements calculated by means of equations (2) to (4), which include the effect of substrate and contact resistances:

$$
\begin{gathered}
R_{\mathrm{eq}}=R_{\mathrm{n}}+R_{\mathrm{p}}+2\left(R_{\mathrm{cn}}+R_{\mathrm{cp}}\right) \\
R_{\mathrm{eq}}=R_{\mathrm{Sn}} \frac{L_{\mathrm{n}}}{W_{\mathrm{n}}}+R_{\mathrm{Sp}} \frac{L_{\mathrm{p}}}{W_{\mathrm{p}}}+2\left(\frac{\rho_{\mathrm{cn}}}{L_{\mathrm{c}} W_{\mathrm{n}}}+\frac{\rho_{\mathrm{cp}}}{L_{\mathrm{c}} W_{\mathrm{p}}}\right), \\
R_{\mathrm{Sn}}=\frac{\rho_{\mathrm{n}}}{H_{\mathrm{n}}}, \quad R_{\mathrm{Sp}}=\frac{\rho_{\mathrm{p}}}{H_{\mathrm{p}}} \\
K_{\mathrm{eq}}=\lambda_{\mathrm{n}} \frac{W_{\mathrm{n}} H_{\mathrm{n}}}{L_{\mathrm{n}}}+\lambda_{\mathrm{p}} \frac{W_{\mathrm{p}} H_{\mathrm{p}}}{L_{\mathrm{p}}}+\lambda_{\mathrm{m}} \frac{W_{\mathrm{m}} H_{\mathrm{m}}}{L_{\mathrm{m}}}
\end{gathered}
$$

where $W$ is the width, $H$ is the height, $L$ is the length, $R_{\mathrm{S}}$ is sheet resistance, $\rho$ is the electrical resistivity, $\rho_{\mathrm{C}}$ is the contact resistivity and $\lambda$ is the thermal conductivity. The indexes $n$, $p, m$ and $c$ refer to the n-type leg, p-type leg, membrane and contact, respectively.

In order to achieve the minimum temperature on the cold side of the device, the hot side must be connected to a highthermally conductive material and to a heat sink, capable of keeping the hot side of the device around RT. This can be achieved in a micro Peltier cooler, for example by the use of a silicon substrate as the heat sink. In the devices fabricated on a polyimide substrate, the heat sink on the hot side is obtained with large metal contact areas, since the substrate has low thermal conductivity and cannot act as heat sink.

Two types of device were simulated using finite-element analysis (figure 2).

- A larger device, with a cold area of $4 \times 4 \mathrm{~mm}^{2}$ : this device rests on a $12 \mu \mathrm{m}$ thick polyimide membrane and has four $\mathrm{p}-\mathrm{n}$ pairs of thermoelectric elements, with dimensions of $2 \mathrm{~mm} \times 1 \mathrm{~mm} \times 10 \mu \mathrm{m}$ each.

- A microdevice, with a cold area of $120 \times 120 \mu \mathrm{m}^{2}$, on top of a $12 \mu \mathrm{m}$ thick polyimide membrane with four $\mathrm{p}-\mathrm{n}$ pairs of thermoelectric elements, with dimensions of $150 \mu \mathrm{m} \times 50 \mu \mathrm{m} \times 10 \mu \mathrm{m}$ each.

A temperature difference of $18{ }^{\circ} \mathrm{C}$ between the hot and cold sides was obtained in the larger device and of $16{ }^{\circ} \mathrm{C}$ in the microdevice. The higher temperature difference achieved
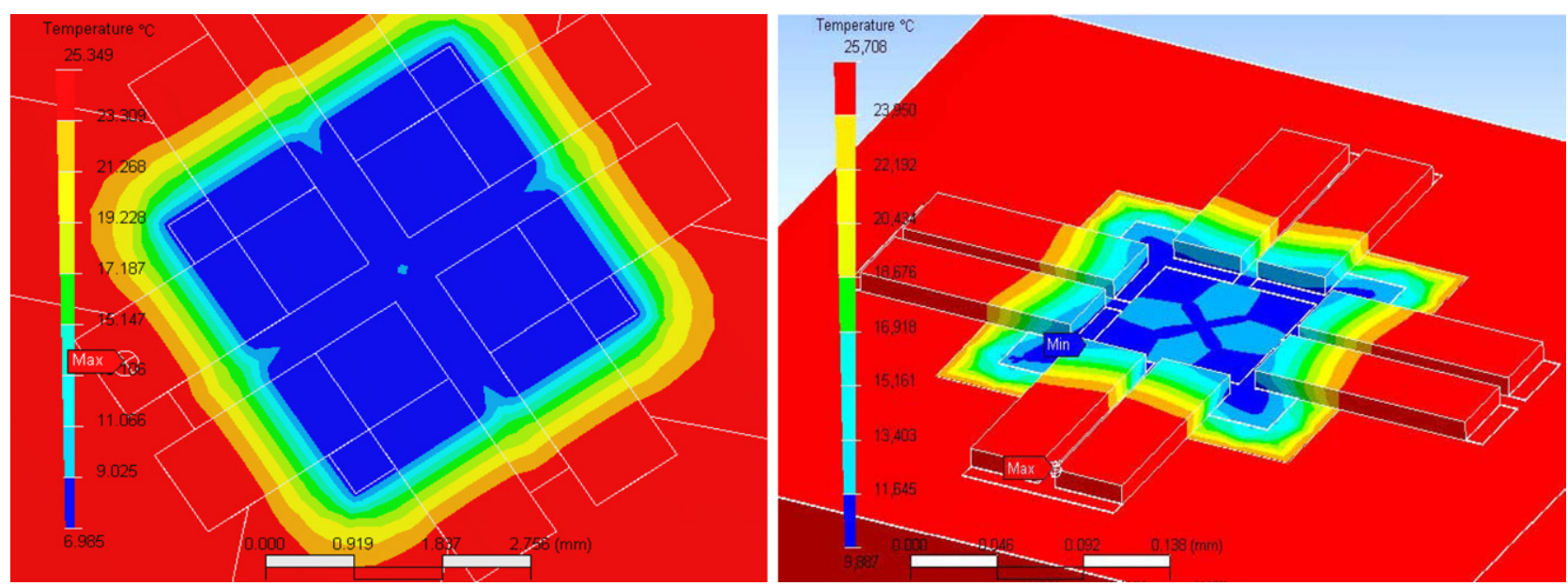

Figure 2. FEM simulation of a small device (left) and a microdevice (right) shows the possibility of achieving a temperature difference between hot and cold sides of $18{ }^{\circ} \mathrm{C}$ and $16^{\circ} \mathrm{C}$, respectively for the small and the microdevices. 


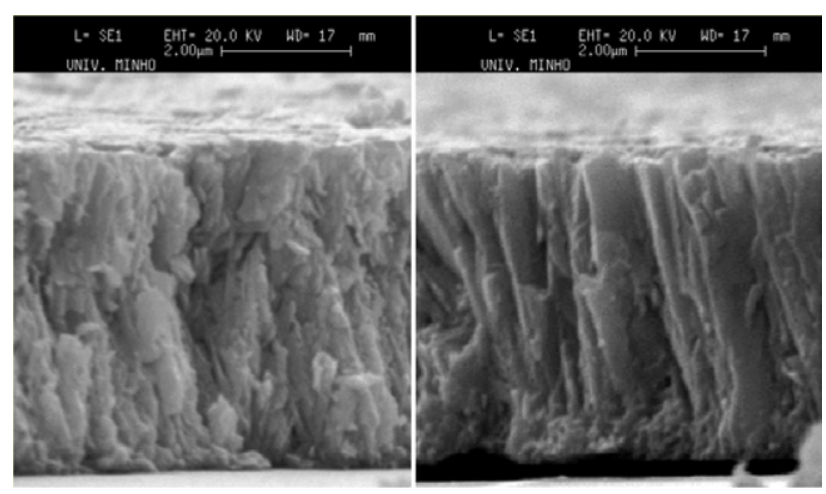

Figure 3. SEM photos of $\mathrm{Sb}_{2} \mathrm{Te}_{3}$ (left) and $\mathrm{Bi}_{2} \mathrm{Te}_{3}$ (right) thin films.

with the larger device compared to the microdevice is due to contact resistance. When the device is scaled down but keeping film thickness constant, the contact resistance $\left(R_{\mathrm{c}}\right)$ between the thermoelectric elements and metal pads increases with the square of the dimensions $L$ and $W$. The electric resistance of the thermoelectric elements $\left(R_{\mathrm{n}}\right.$ and $\left.R_{\mathrm{p}}\right)$ does not change, since it depends only on the sheet resistance which is constant. For this reason, contact resistance becomes an important performance factor when decreasing dimensions of microcoolers.

Thermoelectric properties as referenced in the literature $[8,11]$ were considered in FEM simulations. Thermal loads were applied in the $\mathrm{n}$ and $\mathrm{p}$ junctions, representing Peltier and Joule effects at contact areas (contact resistivity of $10^{-9} \Omega \mathrm{m}^{2}$ was assumed). Heating by the Joule effect was distributed uniformly on the volume of the thermoelectric elements. An optimal current of $25 \mathrm{~mA}$ was considered on a small device and $18 \mathrm{~mA}$ on a microdevice (theoretically calculated). A boundary-fixed temperature $\left(25^{\circ} \mathrm{C}\right)$ was applied on the substrate edge. Thermal convection and radiation losses were simulated with a load of $10 \mathrm{~W} \mathrm{~m}^{-2} \mathrm{~K}^{-1}$, applied in the cooled region, using the still-air convection model provided on the simulation tool. Losses from other areas were neglected, since these areas have temperature near room temperature. No other external load was applied. All simulations were made with an ANSYS(c) package and results agree with theoretical calculations.

\section{Device fabrication}

\subsection{Thin-film deposition}

The thermoelectric performance of thermoelectric materials is characterized by the dimensionless parameter figure of merit (ZT):

$$
\mathrm{ZT}=\frac{\alpha^{2}}{\rho \lambda} T
$$

where $\alpha$ is the Seebeck coefficient, $\rho$ is the electrical resistivity, $\lambda$ is the thermal conductivity and $T$ is the temperature [10]. A material with high Seebeck coefficient, low electrical resistivity and low thermal conductivity will have a high figure of merit and is desirable for use in Peltier devices. Thermoelectric p-type and n-type thin films with high figures of merit were obtained by thermal co-evaporation [11], in a high-vacuum chamber, with a thickness up to $10 \mu \mathrm{m}$ (figure 3). (a)

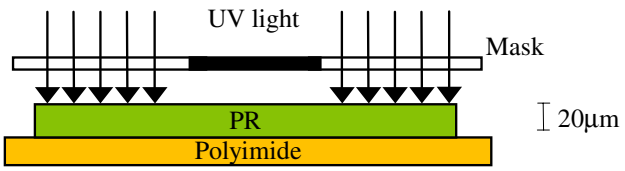

(b)

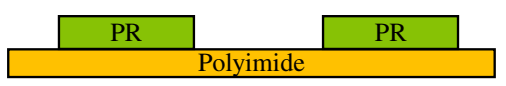

(c)

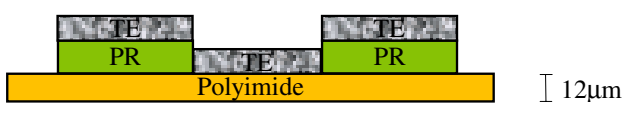

(d)

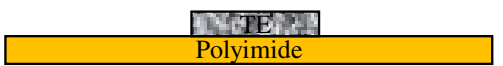

I $10 \mu \mathrm{m}$

Figure 4. Lift-off fabrication process of thermoelectric elements.

Table 1. Summary of the thermoelectric properties of $\mathrm{Bi}_{2} \mathrm{Te}_{3}$ and $\mathrm{Sb}_{2} \mathrm{Te}_{3}$.

\begin{tabular}{llllll}
\hline & \multicolumn{2}{c}{ Composition } & $\begin{array}{l}\text { Seebeck } \\
\left(\mu \mathrm{V}^{\circ} \mathrm{C}^{-1}\right)\end{array}$ & $\begin{array}{l}\text { Resistivity } \\
(\mu \Omega \mathrm{m})\end{array}$ & $\begin{array}{l}\text { Figure merit } \\
(300 \mathrm{~K})^{\mathrm{a}}\end{array}$ \\
\cline { 2 - 5 } Film & $\% \mathrm{Te}$ & $\% \mathrm{Bi}$ or $\mathrm{Sb}$ & -248 & 12.6 & 0.86 \\
$\mathrm{Bi}_{2} \mathrm{Te}_{3}$ & 62 & 38 & 188 & 12.6 & 0.49 \\
$\mathrm{Sb}_{2} \mathrm{Te}_{3}$ & 73 & 27 & & 18.6 & \\
\hline
\end{tabular}

a Thermal conductivity of bulk material $\left(1.7 \mathrm{~W} \mathrm{~m}^{-1} \mathrm{~K}^{-1}\right)$ was assumed on figure of merit calculations.

The substrate temperature and evaporation rates were PID controlled during all the deposition process in order to obtain the desired properties. The thermoelectric properties obtained (Seebeck coefficient equal to $-248 \mu \mathrm{V}^{\circ} \mathrm{C}^{-1}$ and $+188 \mu \mathrm{V}^{\circ} \mathrm{C}^{-1}$ in n- and p-type films respectively and electrical resistivities in the range 10-20 $\mu \Omega \mathrm{m}$ ) make these materials suitable for the fabrication of planar Peltier coolers and thermal microgenerators. Table 1 summarizes the thermoelectric properties and the calculated figure of merit at $300 \mathrm{~K}$.

\subsection{Patterning}

SU-8 negative photoresist (PR) and lift-off techniques were studied as a means to fabricate planar thermoelectric devices with micro dimensions. The epoxy-based material SU-8 offers good properties for the patterning process, such as high mechanical strength, good substrate adhesion and very low sidewall roughness [12]. It is a low cost fabrication process, UV-lithography semiconductor compatible and does not require expensive masks. A spin-coater, a UV light source and a hot-plate are the only hardware requirements.

The negative mask used for patterning the microcooler is fabricated from a regular transparency sheet. The SU-8 has high viscosity, making it appropriate for the required structure height. The fabrication starts with the spinning of sacrificial layers of MicroChem OmniCoat ${ }^{\mathrm{TM}}$ and SU-8 on the substrate. The pre-exposure bake is performed by soft bake at $90{ }^{\circ} \mathrm{C}$ for $2 \mathrm{~h}$ on the hot-plate. After that, the substrate with the PR is exposed to UV light of $80 \mathrm{~mW} \mathrm{~cm}^{-2}$ (figure 4(a)) and developed (figure 4(b)). A suitable solvent (propylene glycol monomethyl ether acetate) dissolves the unexposed resist. SU8 columns are formed on top of the substrate. After that, the 


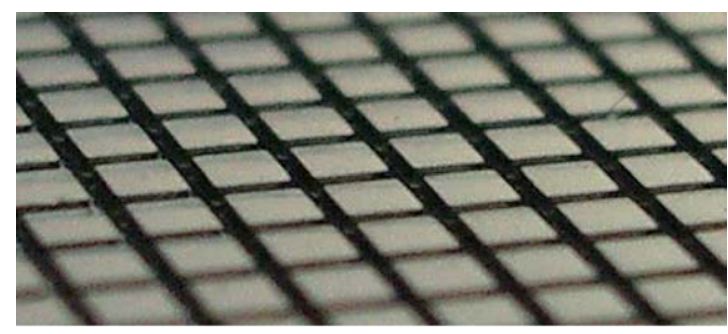

Figure 5. A photo of SU-8 patterned structures.

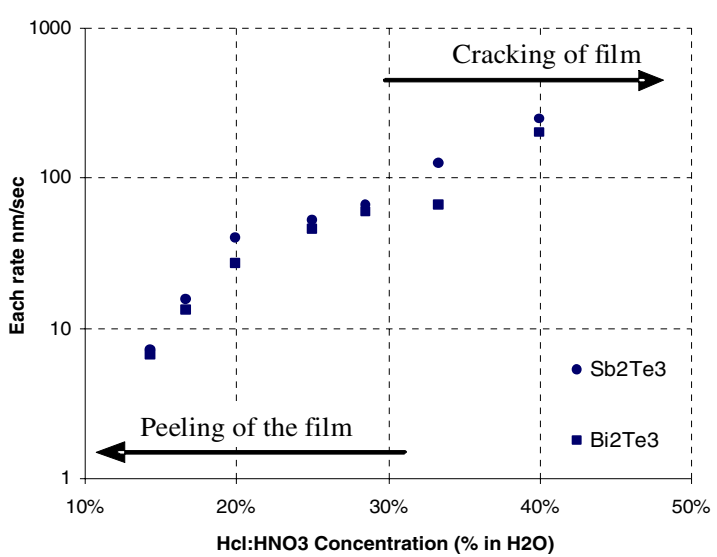

Figure 6. Measured etch rate of $\mathrm{Bi}_{2} \mathrm{Te}_{3}$ and $\mathrm{Sb}_{2} \mathrm{Te}_{3}$ films plotted against acid concentration.

MicroChem OmniCoat ${ }^{\mathrm{TM}}$ must be developed too, with a MCC 101 wet developer. The substrate is then hard-baked using a hot-plate at $90{ }^{\circ} \mathrm{C}$ for $20 \mathrm{~min}$. The thermoelectric material is then deposited on top of the SU-8 (figures 4(c) and 5). Finally the SU-8 and MicroChem OmniCoat ${ }^{\mathrm{TM}}$ are etched (with the MicroChem Remover PG), 'lifting off' the thermoelectric material on top of the PR (figure $4(d)$ ). This process is repeated three times, for the metal contact pads, n-type thermoelectric elements and p-type thermoelectric elements, respectively.

The maximum temperature that the SU- 8 photoresist can support without over hard baking is $170{ }^{\circ} \mathrm{C}$ [1]. Above this temperature, it cannot be removed without damaging the thermoelectric elements. Unfortunately, this temperature limit is below the substrate temperature for fabrication of high quality thermoelectric films. Using a temperature of $170{ }^{\circ} \mathrm{C}$, the figure of merit of both $\mathrm{n}$ - and p-type materials is reduced to less than half of n- and p-type films deposited at ideal substrate temperature [11]. This must be considered when choosing this process.

To allow the use of higher substrate temperatures during film deposition, wet etching techniques were tested and telluride films were patterned using a solution of $\mathrm{HNO}_{3}: \mathrm{HCl}$ (in equal parts) diluted in water. This solution etches $\mathrm{Bi}_{2} \mathrm{Te}_{3}$ and $\mathrm{Sb}_{2} \mathrm{Te}_{3}$ quickly, as shown in figure 6 , and bubbles are released during the process. Etching is complete when bubbling stops and the remaining film covered with PR is immersed in water to stop the etching and minimize undercutting below the mask. Increasing the acid concentration increases the etch rate, resulting in crack failures appearing in the patterned regions [6]. Lowering the acid concentration results in a slower etch rate and allows sufficient time for peeling to occur.

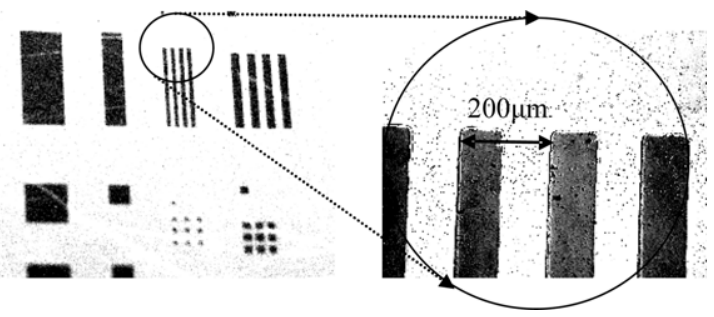

Figure 7. Micrographs of etched $\mathrm{Bi}_{2} \mathrm{Te}_{3}$ structures.

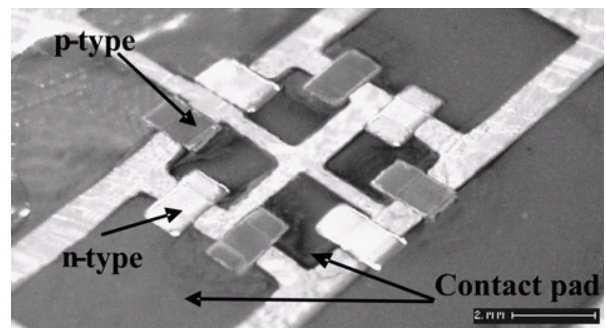

Figure 8. A microcooler device fabricated on top of a polyimide substrate.

To avoid film peeling observed with $\mathrm{HNO}_{3}: \mathrm{HCl}$ solution, an etchant composed of 16:1:1:2 phosphoric acid, nitric acid, acetic acid and water was used to etch both $\mathrm{Bi}_{2} \mathrm{Te}_{3}$ and $\mathrm{Sb}_{2} \mathrm{Te}_{3}$ films deposited on polyimide. The films were previously covered with Transene's PKP negative PR and test structures were patterned (figure 7). Etch rates of $1 \mathrm{~nm} \mathrm{~s}^{-1}$ and $1.5 \mathrm{~nm} \mathrm{~s}^{-1}$ were observed in $\mathrm{Bi}_{2} \mathrm{Te}_{3}$ and $\mathrm{Sb}_{2} \mathrm{Te}_{3}$ films, respectively. Peeling was not detected even after immersing the film in the etchant for $90 \mathrm{~min}$. $\mathrm{Sb}_{2} \mathrm{Te}_{3}$ films were not completely etched and small spots of material were still visible on the substrate surface. Since this etchant etches aluminium, a microcooler with aluminium bottom contacts cannot be fabricated. Figure 7 shows patterned $\mathrm{Bi}_{2} \mathrm{Te}_{3}$ structures on top of the polyimide substrate.

\subsection{A large-area microcooler test structure}

A microcooler was fabricated on top of a polyimide substrate (figure 8) with the same dimensions used in the simulation $(4 \times$ $4 \mathrm{~mm}^{2}$ ). The thermoelectric elements were connected in series using metal contacts, which are fabricated on the substrate by deposition of a $800 \mathrm{~nm}$ layer of aluminium covered with a thin layer $(20 \mathrm{~nm})$ of nickel. Thermoelectric films were deposited on top of contacts, starting with the $\mathrm{Bi}_{2} \mathrm{Te}_{3}$ since it requires higher substrate temperature $\left(270{ }^{\circ} \mathrm{C}\right)$ than $\mathrm{Sb}_{2} \mathrm{Te}_{3}\left(230^{\circ} \mathrm{C}\right)$, thus preventing the re-evaporation of the first thermoelectric layer. Shadow masks were used during the evaporation process to fabricate a thermoelectric device with four pairs of thermoelectric elements. Due to the symmetry of the device, only two masks were required. The first mask defines the contact pads. The second mask defines both the $n-$ and the $p$ type thermoelectric legs, used in succession. This fabrication method allowed a faster test of the thermoelectric materials in a microcooler, overcoming the problems of using wet-etching or lift-off techniques, which will be further addressed in future. 


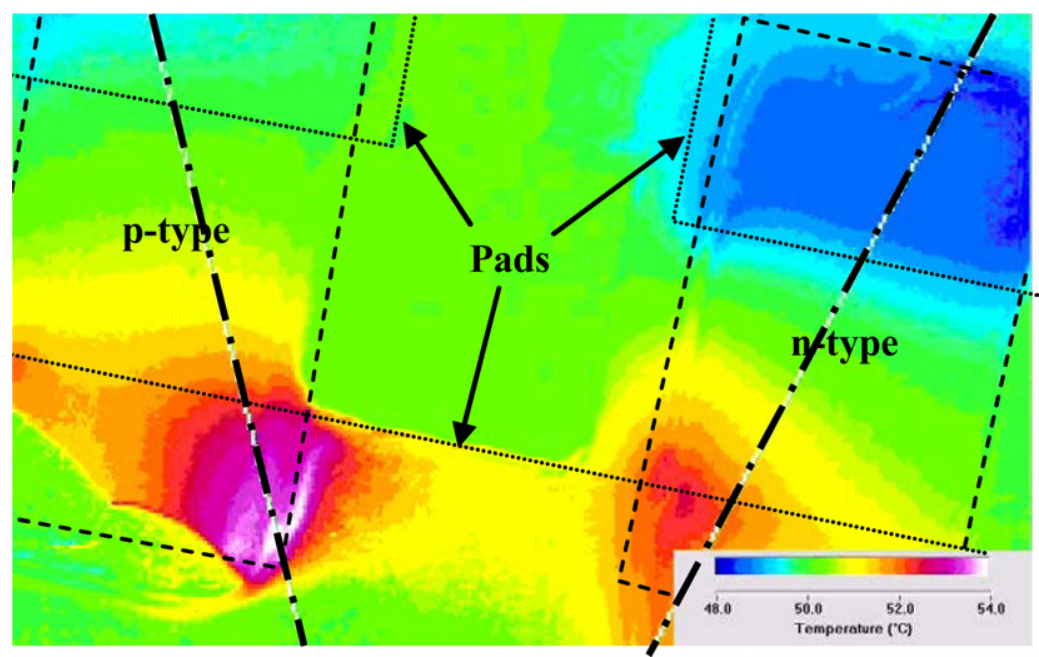

Figure 9. Thermal image of n-type and p-type thermoelectric elements of figure 8, powered with 4 mA current, under vacuum.
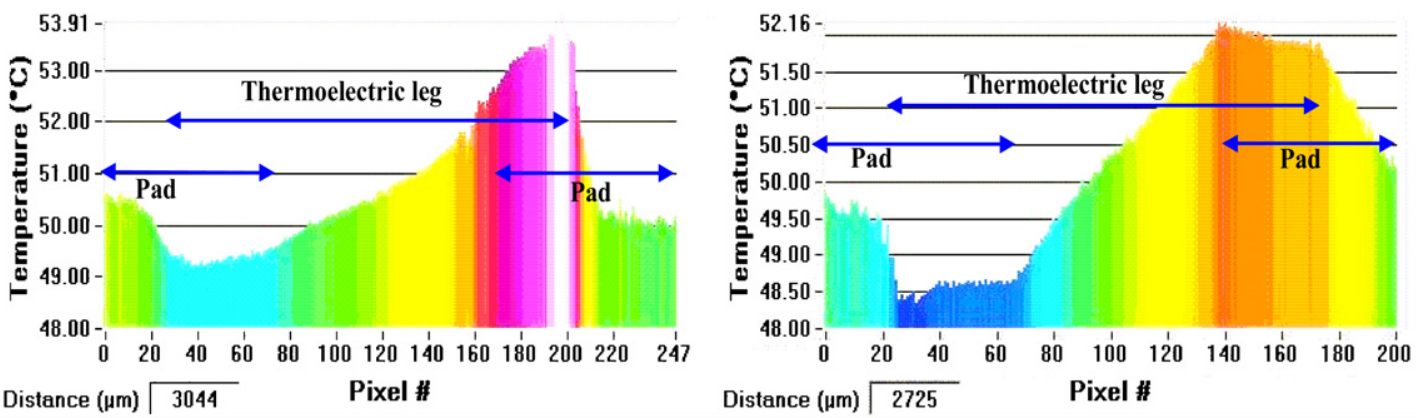

Figure 10. A temperature profile on p-type and n-type thermoelectric legs (left and right graph respectively).

\section{Discussion}

The performance of the microcooler was analysed by use of a thermal image map generated with a microscope equipped with an infrared image sensor. An image under vacuum was obtained with the device excited with a $4 \mathrm{~mA}$ current, and cold and hot sides were clearly identified (figure 9). A temperature difference of $5{ }^{\circ} \mathrm{C}$ between the hot and the cold sides was measured under vacuum (10 mTorr) and $4{ }^{\circ} \mathrm{C}$ under still air conditions. Differences are due to convection losses. Figure 10 shows the temperature profiles along the dashed-dot lines of figure 9.

From the thermal image, it is possible to conclude that thermal contact between the thermoelectric elements and the metal pads is poor since the thermal gradient in this region is quite high, compared with the gradient observed along metals or along thermoelectric elements.

The $5{ }^{\circ} \mathrm{C}$ hot-cold side temperature difference obtained was lower than the value expected from the simulations $\left(18^{\circ} \mathrm{C}\right)$. This difference is due to electrical contact resistance, which is much higher than expected. Contact resistance in this device was of the same order of magnitude as the resistance of the thermoelectric elements $(2 \Omega)$. A small rectifying barrier voltage (less than $80 \mu \mathrm{V}$ ) was measured on metal$\mathrm{Bi}_{2} \mathrm{Te}_{3}$ contacts. The contact resistance was measured using a four-probe method. A current was applied through the metal- thermoelectric element junction. The voltage was measured between a fixed point on the metal side and consecutive points along the direction of current flow. It consists of two terms: an IR drop and the junction built-in voltage. By reversing the current sign it was possible to evaluate both terms.

\section{Conclusions}

Thin-film n-type and p-type thermoelectric materials were deposited, with Seebeck coefficients of $-248 \mu \mathrm{V}{ }^{\circ} \mathrm{C}^{-1}$ and $+188 \mu \mathrm{V}{ }^{\circ} \mathrm{C}^{-1}$, respectively, and resistivity of 10 $20 \mu \Omega \mathrm{m}$. A microcooler, based on the Peltier effect, suitable for integration with microelectronic systems was presented, and the corresponding planar fabrication process was demonstrated. Lift-off and wet etching techniques were compared in patterning thermoelectric materials. A functional device was fabricated and characterized in vacuum and still air, and a temperature difference of $5{ }^{\circ} \mathrm{C}$ was achieved between the hot and cold sides of the device. The flexible concept was demonstrated by the use of a $12 \mu \mathrm{m}$ thickness polyimide substrate.

Future work will pursue lower electrical and thermal contact resistance (using layers of different metals) allowing lower dimension elements and higher thermoelectric performance. Patterning with wet etching techniques will be further investigated to achieve better results, avoiding peeling, 
cracking, incomplete etching and avoiding the etching of the deposited metal contact pads of the device. Microcoolers patterned by wet etching will be fabricated.

\section{Acknowledgments}

This work was supported by ADI (MPYROM) and Portuguese Foundation for Science and Technology (SFRH/BD/18142/2004). The authors also thank H Zou for help in preparing the co-evaporation system and F Volklein for thermal conductivity measurements.

\section{References}

[1] da Silva L W and Kaviany M 2005 Fabrication and measured performance of a first-generation microthermoelectric cooler J. MEMS 141110

[2] Böttner H et al 2004 New thermoelectric components using microsystem technologies J. Microelectromech. Syst. 13 414-20

[3] Snyder G J, Lim J R, Huang C-K and Fleurial J P 2003 Thermoelectric microdevice fabricated by a MEMS-like electrochemical process Nature Mater. Lett. 2 528-31
[4] Venkatasubramanian R, Siivola E, Colpitts T and O'Quinn B 2001 Thin-film thermoelectric devices with high room-temperature figures of merit Nature 413 597-602

[5] Wang W, Jia F, Huang Q and Zhang J 2005 A new type of low power thermoelectric micro-generator fabricated by nanowire array thermoelectric material Microelectron. Eng. 77 223-9

[6] Shafai C 1998 Fabrication of a micro-Peltier device Natl Library Can. p 76

[7] Wijngaards D D L, Kong S H, Bartek M and Wolffenbuttel R F 2000 Design and fabrication of on-chip integrated polySiGe and polySi Peltier devices Sensors Actuators A 85 316-23

[8] Goncalves L M, Couto C, Correia J H, Alpuim P, Min G and Rowe D M 2006 Flexible thin-film planar peltier microcooler ICT'06 (Vienna, Austria)

[9] Volklein F, Min G and Rowe D M 1999 Modelling of a microelectromechanical thermoelectric cooler Sensors Actuators 75 95-101

[10] Rowe D M 1995 Thermoelectric Handbook (Boca Raton, FL: CRC Press)

[11] Goncalves L M, Couto C, Correia J H, Alpuim P, Min G and Rowe D M 2006 Optimization of thermoelectric thin-films deposited by co-evaporation on plastic substrates ECT' 06 (Cardiff, UK)

[12] Gelorme J D, Cox R J and Gutierrez S A R 1989 IBM US Patent 4882245 